América sin Nombre, n.o 21 (2016): 141-165

DOI: 10.14198/AMESN.2016.21.11

ISSN: 1577.3442 / eISSN: 1989-9831

Fecha de recepción: 29/09/2016

Fecha de aceptación: 22/11/2016
Puede citar este artículo como:

Zugasti, Miguel. "Dos ejemplos del teatro cómico breve hispanofilipino: el Entremés del envidioso y el Sarao agitanado entre ocho hombres y mujeres (Manila, 1677)». Teatro breve virreinal. Miguel Zugasti (coordinador). América sin Nombre, 21 (2016): 141-165, DOI: 10.14198/ AMESN.2016.21.11

Link para este artículo: http://dx.doi.org/10.14198/AMESN.2016.21.11

\title{
Dos ejemplos del teatro cómico breve hispanofilipino: el Entremés del envidioso y el Sarao agitanado entre ocho hombres y mujeres (Manila, 1677)
}

\author{
Two Examples of the Hispano-Philippine One-Act Comedy: The Entremés del \\ envidioso and the Sarao agitanado entre ocho hombres y mujeres (Manila, 1677)
}

\author{
Miguel Zugasti* \\ Universidad de Navarra
}

\section{Resumen}

Tras una breve aproximación a la presencia del teatro escrito en español en Filipinas durante el siglo xviI, el artículo se centra en el libro-relación de la Sagrada fiesta, tres veces grande (Manila, 1677), que contiene un total de tres comedias, dos loas, un entremés y un sarao. A continuación se ofrece la edición crítica y anotada del Entremés del envidioso y el Sarao agitanado entre ocho hombres y mujeres, textos que habían permanecido en un olvido casi absoluto desde 1677 hasta hoy.

Palabras clave: Teatro hispanofilipino. Entremés. Sarao. Edición crítica.

\begin{abstract}
After brief survey of theatre written in Spanish in the Philippines during the 17th century, the article focuses on the Sagrada fiesta, tres veces grande (Manila, 1677), a commemorative book containing three plays, two loas, an entremés and a sarao. This is followed by a critical and annotated edition of the Entremés del envidioso and the Sarao agitanado entre ocho hombres y mujeres, texts which have been nearly forgotten from 1677 until now.
\end{abstract}

Keywords: Hispano-Philippine Theater. Entremés. Sarao. Critical edition.

\footnotetext{
* Miguel Zugasti es catedrático de literatura por las Universidades de California Santa Bárbara (2010) y Navarra (2015). Cursó su licenciatura en Filología Hispánica en la Universidad de Salamanca (1986) y se doctoró en la de Navarra (1992). En esta última ejerce la docencia de modo regular, aunque también ha sido profesor visitante en las Universidades de Jawaharlal Nehru (India), Piura (Perú), Kyoto (Japón), Toulouse-Le Mirail (Francia) y California Santa Bárbara (USA). Ha impartido conferencias y cursos varios en países de Europa, América (del Norte y del Sur) y Asia.

Ha publicado una treintena de libros (en su mayoría ediciones críticas de textos áureos) y más de 130 artículos. En ellos se ha ocupado principalmente de autores como Tirso de Molina, Calderón de la Barca, Cervantes, Lope de Vega, Vélez de Guevara, Agustín Moreto, Alonso Remón, Juan Cortés de Tolosa, el Padre Isla... Otros temas de su interés han sido la cuentística medieval y la presencia de América y lo americano en las letras espańolas, con trabajos sobre Lorenzo de las Llamosas, Sor Juana Inés de la Cruz, Juan de Palafox y Mendoza, Ordóńez de Ceballos, el Inca Garcilaso de la Vega y César Vallejo.

Es investigador principal de varios proyectos $\mathrm{I}+\mathrm{D}$ sobre teatro áureo. Dirige la colección de Literatura Hispánica del Departamento de Filología de la Universidad de Navarra. Es miembro del consejo editorial de Rilce y de varias revistas más de ámbito internacional. Asimismo, ha hecho sus pinitos como actor, fundando la compañía de teatro semi-profesional La Contrayerba.

Este artículo forma parte del proyecto Teatro, fiesta y ritual en la monarquía hispánica (ss. XVI-XVII), financiado por la Subdirección General de Proyectos de Investigación: MINECO, referencia: FFI2013-48644-P.
} 
Aunque publicado hace más de un siglo, el clásico libro de Wenceslao E. Retana titulado Noticias histórico-bibliográficas de el teatro en Filipinas desde sus origenes hasta 1898, sigue siendo referencia inexcusable a la hora de acercarnos a la actividad escénica hispanofilipina desarrollada en el archipiélago durante casi trescientos años (ss. XVII-XIX). Posteriores aportes de variado signo, y asimismo de gran mérito, son los de Cabrero, Fernandez, Summers, Irving, Hill y Donoso, entre otros. En paralelo con la praxis dramática implantada en América, Antonio de Morga nos deja temprano testimonio (Sucesos de las Islas Filipinas, 1609) del teatro evangelizador que los misioneros españoles llevaron a Filipinas, cuyos naturales «representan autos y comedias en español y en su lengua con buena gracia, que esto se debe al cuidado y curiosidad de los religiosos, que sin cansarse entienden en su aprovechamiento» $(153)^{1}$.

La primera referencia concreta que cabe citar nos retrotrae a la ciudad de Cebú, en 1598, donde los estudiantes del colegio jesuita agasajaron la visita del obispo Agurto ejecutando una comedia escrita en latín y castellano por un hermano de la Compañía llamado Francisco Vicente Puche (Retana 1910, 19-20; CATEH, ficha 1039). Si pasamos a Manila, en la fundación del Colegio-Seminario de San José, en 1601, vemos que los nuevos colegiales representaron «dos oraciones espańolas» que la crítica interpreta de modo unánime como dos loas (Retana 1910, 21; CATEH, ficha 1040). En líneas generales, el origen del teatro en Filipinas se vincula a la fiesta, sobre todo de índole sacra; buen ejemplo de ello tenemos en la beatificación de Ignacio de Loyola (1609), noticia que llega al archipiélago con dos años de retraso (1611) y que dio lugar a diversos coloquios, diálogos, danzas, loas, comedias, entremeses... escenificados en Manila, Cebú y otros lugares, varios de ellos inspirados en la vida y milagros del nuevo beato (Retana 1910, 23-28; Cabrero 86-88; CATEH, fichas 1047-1052, 1054, 2211). Cabe destacar que algunas de estas composiciones se hiceron en espańol-vascongado o vizcaíno, dato sobre el cual volveremos más adelante.

En 1619 se organizaron nuevos festejos para celebrar la llegada a Manila de una bula papal que autorizaba el culto a la Inmaculada Concepción, momento que se aprovechó para subir a los tablados un buen puñado de comedias como La hermosura de Raquel, Los

1. La cita la repite casi al pie de la letra el dominico fray Alonso Hernández en su Historia eclesiástica de nuestros tiempos, 1611, 298-299 (Retana 1910, 11-12). mártires del Japón, Comedia de la Concepción, La venta de Joseph o El principe de Transilvania (Retana 1910, 28-30; Cabrero 88-89; СATEH, fichas 1055-1056). Años más tarde, en 1630, se celebra un octavario por el culto rendido a los santos del Japón, martirizados en Nagasaki en 1597: hubo fiestas literarias, certámenes poéticos y comedias, además de toros, máscaras y juegos de manos (Retana 1910, 31-32; CATEH, ficha 1057). Poco después, en 1637, al hilo de la conquista de Mindanao, el jesuita Jerónimo Pérez compuso una comedia sobre La toma del pueblo de Corralat y conquista del Cerro, aderezada con su loa, donde los jóvenes colegiales jesuitas volvieron a fungir de actores (Retana 1910, 35-36; CATEH, ficha 1058). Si saltamos tres décadas y llegamos a febrero de 1665, observamos la entronización de una imagen de Nuestra Señora de Guía como patrona de la iglesia de Malate, ocasión para la cual se declamó una loa que hoy se conserva manuscrita en los Anales Ecclesiásticos de Philipinas (Santos I, 199; Irving 397). Poco después, en enero de 1673, observamos que en ese momento -con su consiguiente retraso por razones de lejanía geográficalos jesuitas hicieron múltiples celebraciones en torno a la reciente canonización de san Francisco de Borja (1671) y beatificación de Estanislao de Koska (1670), que pertenecieron a la Compañía, ocasión aprovechada asimismo para honrar a un nuevo miembro del santoral como lo era el rey Fernando III (canonizado en 1671). El relator de los festejos, Joseph Sánchez del Castellar, nos informa de las varias obras teatrales que se montaron al efecto (Hernández Reyes 153155; CATEH, fichas 1030, 2419-2421): una comedia de Jerónimo Ortega sobre la vida de san Francisco de Borja, otras dos sobre san Francisco Javier y el recién beato Estanislao de Koska, otra sobre la conquista de Sevilla por el santo rey don Fernando, una más de Valentín de Céspedes titulada Los amantes de la fee ${ }^{2}$, y por último un entremés o "comedia de burlas» escrito por el propio Sánchez del Castellar (Descripción festiva 8-10). En el caso concreto del entremés, el autor declara su intención de llevarlo a la imprenta (fol. 10r), pero no parece que ocurriera tal cosa ni hay noticias de que se conserve el texto.

He aquí una constante del breve recorrido que acabamos de trazar del arte escénico en Filipinas

2. No se conserva ninguna pieza de Céspedes con este título exacto, aunque la crítica baraja la posibilidad de que se trate del Coloquio de los soldados de la fe, cuyo verso de cierre dice así: «y de la fe los amantes» (CATEH, ficha 1030; Hernández Reyes 154). 
durante sus primeras décadas de vida: disponemos de noticias fehacientes de un puñado de montajes, contamos con los nombres de varios dramaturgos, sabemos incluso los títulos de algunas obras que fueron representadas, pero -excepción hecha de la loa de 1665- falta lo principal, que es la conservación de los textos. Aún hay otra constante a señalar, y es la indiscutible pujanza de la Compañía de Jesús en servirse del teatro en la educación de sus jóvenes escolares y en el adorno de sus fiestas y conmemoraciones. Semejante panorama cambiará por completo en la Manila de 1676 de la mano de los dominicos. Ese año, con el acostumbrado retraso, llega a la capital de Filipinas la noticia de la triple beatificación y confirmación de culto en 1672 de sendos miembros de la Orden de Predicadores: el papa Pío V, Diego de Bebańa y Margarita de Castello. El Colegio y Universidad de Santo Tomás de Aquino que regentan los dominicos en Manila prepara tres días de fiestas (22-24 de noviembre de 1676) con su misa y sermón, amenizado todo ello con un certamen poético, varios villancicos, dos loas, un entremés, un sarao y tres comedias (CATEH, fichas 1061, 1066, 1068-1071 y 2632). Como los dos últimos beatos no eran muy conocidos, la temática festiva giró en torno a Pío V y a santa Rosa de Lima, esta última patrona de Filipinas y el Nuevo Mundo desde 1670, y recién canonizada en 1671. El provincial de la orden en Manila, fray Felipe Pardo ${ }^{3}$, fue el encargado de resumir (o mandar resumir) los actos festivos en un raro impreso que lleva este largo título:

Sagrada fiesta, tres veces grande, que en el discurso de tres días celebró el convento de Sancto Domingo de Manila, primera Casa de la Provincia del Sancto Rosario de Filipinas. En la beatificación de los gloriosos Sanctos Pio Quinto, Diego de Bebaña y Margarita de Castello. Mandada por nuestro Reverendo Padre Maestro Fray Juan Tomás de Rocaberti, Maestro General de toda la sagrada Orden de Predicadores. Y ejecutada por el Reverendo Padre Fray Felipe Pardo, Comisario del Sancto Oficio y Provincial segunda vez de dicha Provincia... Con las licencias del Gobierno y del Ordinario. En Manila, en el Collegio y Universidad de Sancto Tomás de Aquino. Por el Capitán D. Gaspar de los Reyes. Año de 1677.

3. Una amplia reseña biográfica de este dominico (fray Felipe Hernández de Pardo, Valladolid, 1611-Manila, 1689), que fue arzobispo de Filipinas y se vio envuelto en grandes polémicas, se localiza en Ocio y Viana 1891, I, 473-526.
Antes de entrar en materia, a modo de inciso, diremos que en la «Introducción» del libro (fol. 2v) se comenta lo siguiente: «El año pasado de [16]72 celebró esta provincia en su convento de Sancto Domingo de Manila, las cereales de nuestra castísima Rosa del Perú, en concurso de S. Luis Beltrán y de los beatos Alberto Magno, Margartita de Saboya y el sancto rey don Fernando». Entre los actos de las cereales (recuerdo de las fiestas cereales de la antigüedad) hubo "fuegos, comedias y danzas», con tanta relevancia y aparato como no se había visto antes "en estas islas", aunque de nuevo se repite la idea de que no se publicó la habitual relación de las fiestas: «materia pudo ser digna del bronce, cuanto más del estaño ordinario de la imprenta», pero al final «no se atrevió a entrar la estampa, no por falta de ánimo, sino por escrúpulo» (Pardo, Sagrada fiesta $2 v)$. Por suerte no ocurrió tal cosa en 1676, pues en esta ocasión los dominicos sí consiguieron publicar el libro-relación de lo acontecido, otorgando por primera vez gran espacio a las obras dramáticas $-y$ tres sermones- que fueron parte nuclear de los fastos. En

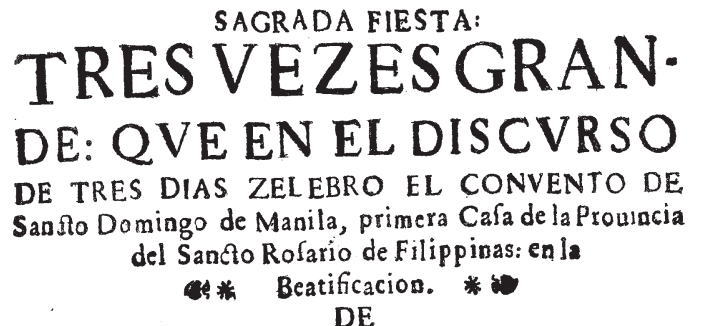
DE

LOS GLORIOSSOS GANCTOS PIO Q VINTO, DIEgo de Bebaña, y Margarita de Cattello: Mandada

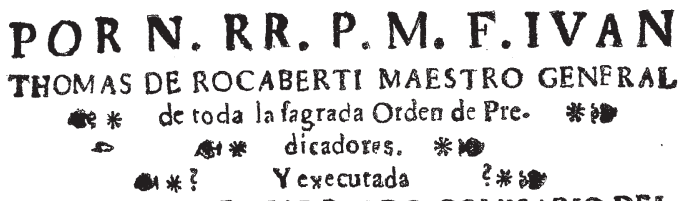

POREL R P.F FELIPPE PARDO COMISARIO DEL Sancto Officio, y Prouincial fegunda vez de dicha Prouino cia, ea cúyo nombre, y en alguna feñal de rendido, fomo eo terno agradezimiento, pone effa delcripcios en los A* Reales, y Supremos Eftrados. DEL

EXCELENTISSIMO SEÑOR CONDE DE MEDE. Jin, Prefidente, y Señotes Confejeros del Real y Suprezo a delasladias. *

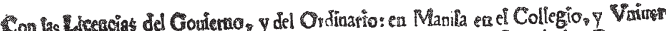
Idad de Sancto 7 homas de Aquino. Por el Capitan D. Gaipar de los Reyges, A Añ de $7 \%$ \%

Portada del ejemplar de la Biblioteca Nacional de Filipinas 
palabras de Retana, estamos aquí ante «las primeras piezas teatrales impresas en Filipinas» $(1910,40)$.

La Sagrada fiesta, tres veces grande, es un volumen de tamaño cuarto, compuesto por un pliego de a cuatro para los preliminares y 142 hojas de texto, con estas signaturas: [ ]4 + A-O4, P2, $4,94,94,9$, V-Z4, Aa-Ee4, Ff2, 44, 4, 94, Ll-Nn4, Oo2. Retana informa de la extrema rareza del libro, del cual alcanzó a ver un solo ejemplar, cuya portada reproduce en facsímil, y que nosotros repetimos aquí de nuevo (1906, 153-155).

Dicho ejemplar perteneció al bibliófilo Pedro Vindel, quien en 1911 lo anunciaba por 6000 pesetas en el catálogo de su prestigiosa librería (Vindel I, 232-234). Poco después fue adquirido por la Compañía General de Tabacos de Filipinas, conducto por el cual acabó llegando a la Biblioteca Nacional de Filipinas (registro actual: Fil 270.092 Sa18 1677). Martín Rodrigo nos da pistas de cómo se ejecutó la operación:

$\mathrm{Al}$ poco de su fundación [Tabacalera] fue creando, en sus oficinas de Barcelona, una verdadera biblioteca, cuya diversidad y riqueza iban más allá del mundo estrictamente empresarial. Una biblioteca privada que fue atesorando numerosos libros de gran interés para los filipinos, en general, y para los estudiosos de la economía, la historia, la geografía o la cultura de Filipinas, en particular. Tabacalera se dedicó a comprar a libreros de todo el mundo numerosos volúmenes editados en diferentes lenguas y lugares; unas monografías cuyo denominador común era su temática filipina. Por si fuera poco, compró en 1900 la biblioteca particular del prestigioso intelectual filipinista Wenceslao E. Retana y en 1904 realizó una voluminosa compra a un librero madrileño. Tabacalera encargó entonces al propio Retana que elaborase un catálogo de su biblioteca, dando pie al conocido Aparato Bibliográfico de la Historia general de Filipinas, editada finalmente en 1907. Se calcula en 4.623 el número de volúmenes que conformaban entonces aquella prestigiosa Biblioteca Filipina de la Tabacalera, sin duda la más importante en el planeta sobre asuntos filipinos. Una gran biblioteca que sería finalmente vendida, en 1913, al gobierno del país para que sus volúmenes viajasen de Barcelona a Manila y se incorporasen a la futura Biblioteca Nacional de Filipinas, formando desde entonces parte del patrimonio documental propio del pueblo filipino.

El ejemplar está en muy precario estado de conservación, le faltan dos folios (86 y 87) y en general

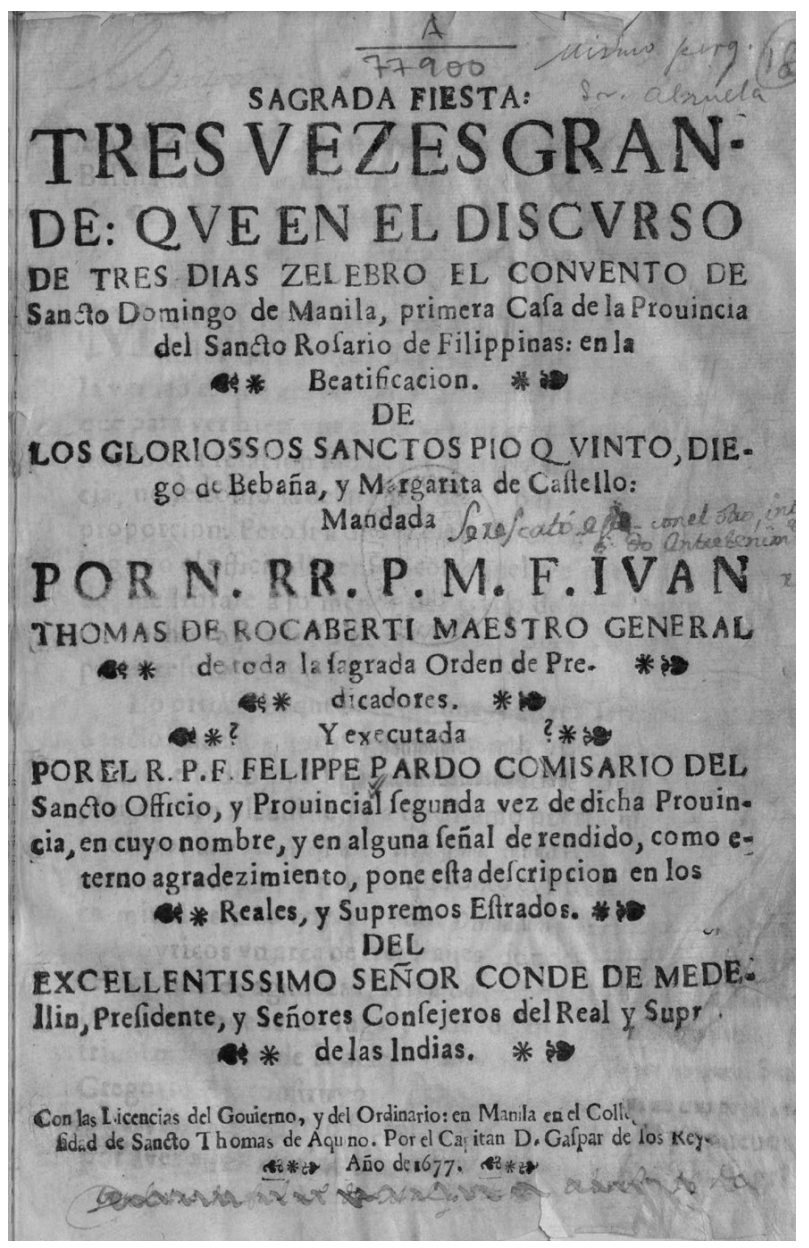

Portada del ejemplar de la Linga Bibliothek, Universidad de Hamburgo

todo él resulta de difícil lectura. Por nuestra parte, podemos añadir que hemos localizado un segundo ejemplar en la Linga-Bibliothek de la Universidad de Hamburgo (signatura: Linga Bh 57) ${ }^{4}$. Está completo y bastante mejor conservado que el anterior, lo cual ha facilitado en extremo nuestro trabajo 5 .

En grueso, este raro libro de la Sagrada fiesta, tres veces grande, se estructura así:

4. Ya informábamos de su existencia en Zugasti 2013, 127. En el centro de la portada, en un pequeńo espacio en blanco, una mano con caligrafía antigua escribe esto: «Se rescató este, con el otro intitulado Entretenimiento, en diez reales».

5. En dos ocasiones (folio inicial y fol. 58r) aparecen sendos ex libris manuscritos declarando que el ejemplar perteneció al oratorio de san Felipe Neri de Puebla de los Ángeles. Asimismo, en el vuelto del último folio está escrito a mano el nombre de «Vicente Rosete». 
- Portada y preliminares (primer pliego, sin paginar).

- Introducción a las fiestas (fols. 1r-15v).

- Sermón primero a la beatificación de Pío V, predicado por Miguel Ortiz de Covarrubias el domingo 22 de noviembre de 1676 (fols. 16r-33r).

- Celebridad del segundo día y sermón segundo, a la beatificación de Margarita de Castello, predicado por fray Diego de San Román (fols. 33r-47r).

- Celebridad del tercer día y sermón tercero, a Diego de Bebaña, predicado por fray Manuel de Mercadillo (fols. 47r-58r).

- Loa a las fiestas de los beatos Pio V, Diego de Bebaña y Margarita de Castello (fols. 59r-61r).

- El gobierno milagroso del santo Pio Quinto, Pontifice Máximo, comedia nueva (fols. 62r-85r).

- Entremés del envidioso (fols. 85v-88v).

- Sarao agitanado entre ocho hombres y mujeres (fols. 88v-89v).

- Loa segunda en las fiestas de los tres sanctos, para el Collegio de San Juan de Letrán (fols. 90r-92r).

- Comedia nueva. Los albores de la Rosa (fols. $92 \mathrm{v}-112 \mathrm{r})$.

- Comedia. Las virtudes de la Rosa (fols. 113r-142r).

Fray Felipe Pardo, que a la sazón ejercía su cuarto año de mandato en la Provincia del Santo Rosario de Filipinas (estaba en su segundo nombramiento como provincial), es el relator o narrador de los festejos; conocemos también los nombres de los tres clérigos que predicaron otros tantos sermones; pero se nos resiste todavía la identidad del dominico que escribió todas las piezas teatrales (tres comedias, dos loas, un entremés y un sarao), así como la mayor parte del resto de poemas o villancicos aquí reunidos. A falta de datos fehacientes, he aquí lo que declara el texto sobre este particular:

Es fuerza dar razón de la obra de las tres comedias que van impresas abajo, y aquí no viene mal, y se estará dicho. Todas tres comedias, entremés y loas, y los más de los poemas que quedan arriba, tienen por autor a un religioso de esta Provincia aficionado al arte, que habiéndose estrenado en las dos comedias de Santa Rosa (que hizo sin más fin que el de poner en números para sus solas, y un ri[n]cón de la celda su devoción a la santa), no las pudo encerrar tanto que no las viesen algunos amigos. De estos pasaron al Padre Provincial, antes de serlo esta segunda vez, y ahora hallándose con la especie y con el empeño de estas fiestas, le mandó que hiciese la de el Santo Pío Quinto para que se representase; y de camino (atándole a la verdad de la historia) limpiase de algunas impropiedades bien intolerables y mal soñadas la comedia antigua que años ha que anda impresa por ahí de un auctor de fama, aunque quizá se la echaron a la puerta. Como al fin fue ésta hija de la obediencia, salió bastante, y tuvo aceptación, porque la acertaron a representar los collegiales de nuestro Collegio de Sancto Tomás con dicha; en que puso buena, o la mejor parte, un vecino de Manila secular y devoto de nuestra religión, que hizo la persona de Pío Quinto con aquella auctoridad y viveza que no supiera adelantar el famoso Prado. Vistiéronse los personajes de auctorizadas ropas, guardia y comitiva, en que sin duda va agraviada la comedia en la impresión, pues lo mejor que tuvo no se puede trasladar. De suerte que todas tres comedias son nuevas, jamás vistas, que en ser de persona que no lo tiene de profesión, ni menos el curso que piden estas obras para darles lugar entre las musas tan divinas que hoy logra nuestra España, llevara su pedazo de disculpa (Sagrada fiesta, fol. 46).

De las tres comedias que entran en colación, nótese cómo fray Felipe Pardo destaca el caso de la dedicada al papa Pío V, pues ya corría impresa una al efecto a nombre de un dramaturgo de prestigio, y considera que esta nueva comedia escrita ahora en Manila (El gobierno milagroso del santo Pío Quinto) la supera. Pienso que alude a La milagrosa elección, publicada a nombre de Agustín Moreto (Parte treinta y nueve de comedias nuevas, 1673), aunque se considera de dudosa atribución, con otros posibles candidatos a la autoría como Pérez de Montalbán o Felipe Godínez. Para saber más sobre las dos comedias restantes (inspiradas ambas en la vida de santa Rosa de Lima: Los albores de la Rosa y Las virtudes de la Rosa), es preciso retomar la información estractada en el libro de la Sagrada fiesta, tres veces grande:

A la tarde de este día [lunes 23 de noviembre de 1676] se le había determinado [a un dominico] la ocupación de una comedia: Los albores de la Rosa, que es la segunda en orden que se pone adelante. Teníanla repartida los estudiantes manteístas de nuestra Universidad de Sancto Tomás. Hubo accidente que impidió su representación, y el mayor fue el poco tiempo. Mas no faltó entretenimiento que en parte llenara este vacío, porque se trajeron unos Sianes [de 
Siam] volatines que, con varias demonstraciones de ligereza y fuerzas, suplieron y alegraron (fol. 46r).

El tercer día [24 de noviembre] por la tarde se representó la que es segunda comedia de Santa Rosa: Las virtudes de la Rosa. Hízola el Collegio de San Juan de Letrán, que también envía sus collegiales a estudiar a Sancto Tomás, y su gobierno y educación corre por cuenta de nuestra Provincia. Representáronla muy bien, y fue muy bien oída de la ciudad. Si la sancta se diere por servida, tiene el auctor intento de aplicarse a la tercera que falta, y lleva idea de su sagrado tránsito, con título de Los desmayos de la Rosa. Con eso será menor la imperfección. Basta esto cuanto a las comedias (fols. 46v-47r).

No se desliza ni una palabra más sobre el autor que compuso las tres comedias, que es el mismo del Entremés del envidioso y el Sarao agitanado entre ocho hombres y mujeres que ahora nos ocupan. Aunque estamos abocados a la anonimia, sí es seguro que se trata de un dominico amante de la poesía, quizás maestro o lector de alguna cátedra en el Colegio de Santo Tomás de Aquino. Pienso además que bien pudo ser un fraile español de origen vascongado, afincado en la Manila de 1676 (Zugasti 2014, 396-397). Aunque nos movemos en el plano conjetural, esto lo deduzco porque en la trama de Las virtudes de la Rosa dos de sus personajes (Don García y Don Vicente) entroncan con Durango (País Vasco), villa cuyo nombre se repite en cinco ocasiones. El texto evoca varias veces la plácida Vizcaya y hace juegos con el habla vizcaína, incluyendo un verso que remeda el idioma vascuence:

Mayo Juras a Dios que si vuelves juicios Durango enteros, cuelgas iglesia mayor milagros cuentas de cuentos.

García No me acuerdes de Vizcaya, porque tras del pensamiento se irán todas las memorias una por una ocurriendo.

(Sagrada fiesta, fol. 115v)

MaYo

¡Oh, mi amo, estoy reventando de contento! ¡Albricias, albricias, Juancho, pides, que en lazos tenemos zorras haces mortecinas! Astua Vicentua muertua.

(Sagrada fiesta, fol. 137r)
Estos chistes con el habla vizcaina son típicos de la época y no es necesario ser de cuna vasca ni dominar su idioma para jugar del vocablo con ellos. Cervantes, Quevedo y muchos otros ingenios del barroco así lo atestiguan; ya hemos visto además que en la propia Manila, en 1611, se declamaron textos en español-vascongado o vizcaíno al hilo de la beatificación de Ignacio de Loyola, quien no por casualidad era de origen vasco. Dicho esto, el chiste del último verso citado "Astua Vicentua muertua» es de otro calibre y sí implica un conocimiento más profundo del vascuence, donde la palabra astua (o astoa) significa 'burro, asno'; de modo que el verso se puede traducir algo así como «el burro de Vicente se ha muerto", lo cual casa bien con la acción de la comedia, que nos remite al caballero don Vicente y a la amenaza de muerte que deviene de su reto a duelo, según explicará el gracioso Mayo pocos versos más abajo. Dado que en el volumen de la Sagrada fiesta se dice que "todas tres comedias, entremés y loas, y los más de los poemas que quedan arriba, tienen por autor a un religioso de esta Provincia aficionado al arte» (fol. 46r), cabe pensar que nuestro dramaturgo bien pudo ser un dominico de origen vasco, o al menos alguien con un conocimiento básico de dicho idioma.

Somos conscientes de que nuestra deducción no resuelve el problema de la anonimia ni nos saca del plano conjetural, pero quizás sirva para arrojar algo de luz sobre esta cuestión. Hemos revisado la muy documentada Reseña biográfica de los religiosos de la provincia del Santísimo Rosario de Filipinas desde su fundación hasta nuestros dias, de Hilario María Ocio y Viana (1891, 2 vols.), sin obtener tampoco resultados concluyentes. Aquí se cita, por ejemplo, a un fray Diego de San Román, natural de Álava, quien en el capítulo de la Orden de 1665 fue nombrado rector del Colegio-Universidad de Santo Tomás, además de lector de prima y regente de estudios (Ocio y Viana 1891, II, 5-7). También localizamos a otro fraile de origen alavés llamado Juan Ibáñez de Santo Domingo, que llegó a Manila en 1671; enseñó teología y filosofía en Santo Tomás y fue regente de estudios (Ocio y Viana 1891, II, 157-159). La misma fuente nos habla de otro fraile natural de las montañas de Burgos llamado José Polanco, del cual hay dudas sobre la fecha de su llegada a Filipinas, oscilando entre los ańos de 1671 (Ocio y Viana 1891, II, 189-192) o de 1675 (Ocio y Viana 1895, 241-242). De este último dominico se consigna que compuso «muchas oraciones y versos devotos» en honor de la Virgen (Ocio y Viana 
1891, II, 191), y más tarde se añade que «escribió una colección de oraciones piadosas para uso de sus neófitos, y muchas poesías devotas y elegantes en alabanza de Nuestra Señora y Santa Rosa de Lima, que han desaparecido» (Ocio y Viana, 1891, Índice, 501). Cualquiera de ellos cumpliría los requisitos para ser el autor de todas estas piezas de teatro estrenadas en Manila en 1676, pero con los datos de que disponemos no es posible asegurar nada y seguimos moviéndonos en el resbaladizo terreno de las hipótesis.

\section{Edición del Entremés y el Sarao}

Este año de 2016 se conmemora el octavo centenario de la fundación de la Orden de Predicadores por Domingo de Guzmán en Toulouse, en el contexto de la cruzada albigense. Como pequeña contribución personal al evento, a continuación procedo a editar las dos piezas de teatro cómico breve que se incluyeron en el volumen de la Sagrada fiesta, tres veces grande (Manila, 1677). Se trata del Entremés del envidioso y del Sarao agitanado entre ocho hombres y mujeres $^{6}$. No hace falta insistir mucho en la relevancia de este rescate textual: ninguna de estas obras se ha vuelto a publicar desde 1677; su desconocimiento casi total hace que no aparezcan en los catálogos de teatro breve al uso, así que tampoco disponemos de aproximaciones críticas que vayan más allá de la leve mención de su remota existencia. Añádase a esto la cuestión -no menor- de la conservación material de los originales; como queda dicho, solo nos consta la existencia de dos ejemplares de la Sagrada fiesta, tres veces grande, custodiados en la Biblioteca Nacional de Filipinas y en la Linga-Bibliothek de la Universidad de Hamburgo, instituciones ambas a las que agradecemos las facilidades otorgadas para el manejo directo de sus fondos.

El Entremés del envidioso ocupa los folios 85v$88 \mathrm{v}$ del impreso citado. Por desgracia, el ejemplar de la Biblioteca Nacional de Filipinas está mutilado y carece de los folios 86 y 87, con lo que se pierden casi dos terceras partes del texto: faltan 192 versos -del 66 al 257, ambos inclusive- sobre un total de 309. Afortunadamente el ejemplar de Hamburgo está completo y en muy buen estado de conservación,

6. Para una ocasión futura quedan las dos loas (nuevos ejemplos de teatro breve, pero no cómico) y las tres comedias, cuya edición integral estamos acometiendo. lo cual nos ha permitido recuperar el texto íntegro. El Entremés del envidioso basa su comicidad en el manejo de varias figuras ridículas, de honda raigambre popular, ya topiquizadas, como son un Alcalde y su inseparable Regidor, que dirimen sus diferencias sobre las tablas acompañados de un Alguacil, un viejo Barbero y su hija Garbosa, más un estudiante fanfarrón llamado Perucho. Todo ello escrito en un registro coloquial y burlesco, trufado de prevaricaciones lingüísticas que acentúan la rusticidad e ignorancia de los hablantes: tal por ejemplo decir espontaña portesta por 'espontánea protesta' (v. 4), concencia por 'conciencia' (v. 6), huerzan por 'fuerzan' (v. 14), vus mete por 'os mete' (v. 17), etc. En las notas al pie que acompañan al texto registro los casos más notables de esta práctica. Junto a estas notas filológicas, la edición contiene otras notas ecdóticas donde dejo constancia de mis intervenciones en el texto príncipe (al que llamo P), sobre todo para subsanar erratas.

El núcleo de la acción arranca con unas lastimeras quejas del Alcalde ante el acoso que sufre de un Regidor, quien le envidia en todo lo que hace y dice. Por boca del Regidor el público se entera de que su envidia oculta un enigma: todo es cantaleta ('mofa, burla') para que el Alcalde le tome ojeriza (v. 133) y, harto del envidioso, actúe a la contraria (v. 139) de como lo hace su Regidor. El entremés se divide en dos partes muy claras, que se diferencian asimismo por el uso de la métrica: esta primera parte se vale del romance (vv. 1-150, con rima é-a), mientras que la segunda parte recurre a la silva de consonantes (vv. 151-304), coronada con unos versos de cierre irregulares (vv. 305-309). En la segunda parte entran en acción un viejo Barbero y su hija Garbosa, de quienes se mofará a su gusto un estudiante que llega de Alcalá a Filipinas, llamado Perucho. Este supuesto estudiante es un fanfarrón iletrado con nulo interés por los libros ("Cuanto a mi inclinación, maldita aquella / tuve a estudiar gramática, ni a olella», vv. 175-176), pero que sí demuestra ser más diestro en el arte de la quiromancia y decir la ventura. Al final, este Perucho será quien dé la solución al atribulado Alcalde para sacarse al Regidor de encima, con esta sencilla receta: "a un envidioso, echarle otro envidioso» (v. 266). Esto es, a partir de aquí el Alcalde empieza a firgir que él también envidia al Regidor, hasta que ambos se cansan del juego y ponen fin a su graciosa pendencia.

El Sarao agitanado entre ocho hombres y mujeres es un texto muy diferente al del entremés, con una dramaticidad más atenuada, que se mueve en la vaga 
frontera que surge entre artes hermanas como son la danza y el teatro. Aquí el sarao hace las veces de fin de fiesta, denominación utilizada en otros contextos dramáticos, como bien se declara en los vv. 113114: «Ya parece que va a rematarse, / por no dar en cansado, el festejo» ${ }^{7}$. Entiendo que todo el sarao se ejecuta cantado, con mezcla de ritmos y movimientos contrapuestos como son los de la pavana y la gallarda, con intervención de cuatro parejas de hombres y mujeres vestidos a lo gitano (agitanados). Dividido en cuatro partes, en la primera (vv. 1-28) salen a escena las guías («la persona que en los saraos, bailes o danzas lleva tras sí a las demás de su coro o hilera", Autoridades), quienes "van recibiendo a los otros» (acotación inicial). Se cantan siete coplas asonantadas para celebrar a "los tres de la fama / que hoy honra la Iglesia» (vv. 1-2), esto es, los tres nuevos beatos (Pío V, Diego de Bebańa y Margarita de Castello, todos ellos dominicos). La segunda parte (vv. 29-60) consiste en una pavana («especie de danza española que se ejecuta con mucha gravedad, seriedad y mesura», Autoridades), con cuatro coplas cuyo remate es un verso que se repite a modo de estribillo: «tres hachas tiene más». La tercera parte (vv. 61-92) contiene la danza de una gallarda, que contrasta con la anterior por tratarse de movimientos más enérgicos y pronunciados. Consta de ocho coplas asonantadas, con el interés ańadido de que sus versos dejan entrever la variedad del público congregado en Manila para presenciar el espectáculo: la Audiencia y el Tribunal reales, los Cabildos civil y religioso, el Regimiento militar, el clero secular y regular, así como damas y nobles de toda la ciudad. Concluye el sarao con unas coplas de despedida (vv. 93-128), donde se pone énfasis en que la salida de los danzantes se haga de modo reglado, en orden, abandonando el escenario por parejas:

Mas por no retirarse de tropa, hagan dos el retiro primero.

Por el mismo concierto les siguen, no sin quejas, los dos compañeros, que su breve cortejo se acaba y se queda en su ser el empeño. Para hacer el forzoso vïaje los siguientes se van disponiendo, por que llegue a gozarse acabado lo que aspira a mirarse perfecto. Tengan fin, adalidades bizarros, la destreza, el cuidado y el juego, y la que es reverencia a los santos sea cortés al teatro respeto. (vv. 115-128)
7. Otros saraos virreinales utilizados para cerrar festejos dramáticos son, por ejemplo, el Sarao de cuatro naciones de Sor Juana Inés de la Cruz (México, h. 1684) y el Sarao de los planetas (Lima, 1725) de Jerónimo Fernández de Castro. La misma función desempeña el Fin de fiesta con que fray Francisco del Castillo remata su festejo para la comedia El redentor no nacido, mártir, confesor y virgen, San Ramón (Lima, h. 1749). 


\section{ENTREMÉS DEL ENVIDIOSO \\ Personas}

$\begin{array}{ll}\text { Alcalde } & \text { Barbero, vejete } \\ \text { Regidor } & \text { Perucho } \\ \text { Alguacil } & \text { Garbosa }\end{array}$

\section{Salen el Alcalde y el Regidor}

AlCAlde

Digo, y lo vuelvo a decir, y por esta vara y media hago juramento en forma y una espontańa portesta, que no quiero ser alcalde, y que en Dios y en mi concencia digo que el tomarme bulla es pecado de alatema, y que hago de la vara renunciación, resistencia, repulsa, resignación, remisión, retrato, resta. ¡Yo no quiero ser alcalde! ¿Que me huerzan, que me huerzan!

\section{Sale el Alguacil}

Alguacil

Alcalde

Alguacil

Alcalde

Alguacil Alcalde
Señor Alcalde, ¿qué es esto? Diga, ¿qué voces son estas? ¿Qué voces?

\section{Sí.}

¿Y quién vus mete,

Alguacil hecho de piezas, menistro de matamoscas, a vos con los que vocean? Pues íos por esas iglesias e id agarrando cantores, que dan voces que se quiebran.

v. 2 vara: la 'vara de mando' que lleva el alcalde y simboliza su autoridad. Pero nótese que él dice "vara y media», con lo cual ya desde el principio estamos en el registro cómico burlesco propio del género entremesil.

v. 4 espontaña portesta: 'espontánea protesta'.

v. 6 concencia: 'conciencia'; en Dios y en mi concencia: frase hecha que recoge Correas, Vocabulario, p. 927: «En Dios y en mi conciencia. Juramento, más usado de hombres».

v. 8 pecado] peccado $P$; alatema: 'anatema'.

v. 14 huerzan: 'fuerzan'.

v. 17 vus mete: 'os mete'.

v. 18 hecho de piezas: 'troceado', pero a la vez con carga irónica y despectiva en el sustantivo pieza, pues Correas nos recuerda que la expresión buena pieza se utiliza con «ironía para decir que es taimado y bellaco» (Vocabulario, p. 868).

v. 21 ¿Si hay voces no he de acudir?: porque es obligación de los alguaciles acudir en socorro de quienes vocean pidiendo ayuda.

v. 24 dan voces que se quiebran: porque cantan muy mal, en juego de palabras entre cantores y canto, voz esta última que dilógicamente remite a 'piedra', con la cual se puede quebrar algo. 
Alguacil

Alcalde

Alguacil Alcalde
Cierto, que le tengo envidia

de ver lo bien que se queja.

¿Veis? ¡Ay, mirad qué presto

dimos con el asno en tierra!

Alguacil, ¿sabéis acaso

dónde habrá por ahí una cueva?

30

No de Albaña o Clemesín,

porque esas están muy cerca,

sino allá, allá en Felepinas,

enfrente de las Batuecas.

¿Pues qué en la cueva queréis?

35

Irme a hacer penitencia

a abrirme este cuerpo a azotes,

darme más de sovecientas

bofetadas, rempujones,

cimbrones, sobas, podencas,

cordelejos, varapalos,

pan de perros y de perras...,

allí donde mis sospiros

no haya gentes que los vean.

Pues decidme, si esta villa

su Alcalde, que non debiera,

me hizo y me dio aqueste

Regedor que es una bestia,

que sobre todas sus faltas

de andarse tras mí no cesa:

duende, fantasma, estantino,

vv. 27-28 qué presto / dimos con el asno en tierra: 'qué pronto nos topamos con el problema' (o sea, con el asno del Alguacil). Remite a la frase hecha «Dar con ello en tierra» (Correas, Vocabulario, p. 892). Los versos connotan también la idea de enfado y fastidio, según se desprende de esta otra expresión: «Echarse con la carga. Por acabarse de enojar con efecto; dar con todo en tierra, perdiendo la paciencia y sufrimiento. Comparación de la bestia que se echa con la carga, por no poder sufrirla ni llevarla» (Correas, Vocabulario, p. 921).

v. 31 Albaña, Clemesín: la forma Albaña remite a veces a la más común de Albania (Diccionario histórico de la lengua española); no documento cuevas nigrománticas en Albania, aunque de dicha región procede la famosa shtriga o bruja vampírica; Moreto cita Albania en su entremés de Las brujas (v. 2). Por su parte, la cueva de Clemesín remite a la cueva o peña Camosina, Camasia, Camasía, Carmesí, Clemesit, Clemesi, Clemesí... que aparece en múltiples textos de temática hechicera y brujeril, y que a la larga se acaba identificando con la famosa cueva de Salamanca. Esta cueva se ubicaba en la cripta de la salmantina iglesia de San Ciprián o San Cebrián (convertida hoy en espacio de reclamo turístico), donde según la leyenda el diablo enseñaba nigromancia; allí pasó el Marqués de Villena siete años estudiando alquimia y ciencias ocultas, hasta que cosiguió engañar al diablo con una estratagema y salvar su alma. Al parecer, el sacristán de la citada iglesia se llamaba Clemente Potosí (citado por Francisco Torreblanca en 1618, y después por el Padre Feijoo, entre otros), de donde surgiría el término Clemesí o Clemesín. Ver al efecto el minucioso estudio de Simonatti (2015), así como los precisos apuntes de Lara (2014, pp. 403-404), de quien entresaco la presente cita: «Y entre ellos un estudiante / (debió ser de la Peña / Clemesi, adonde el diablo / le enseñó la Magia Negra) / al toro embiste».

vv. 33-34 Felepinas, Batuecas: para la mentalidad española y criolla de la época, los topónimos de Filipinas y Batuecas remiten a tierras remotas, lejanas y de difícil acceso. La mención de Filipinas en un entremés escrito y representado en Manila apela directamente al público local y busca su sonrisa cómplice, más aún si se dice que se ubican enfrente de las Batuecas (zona del oeste español, entre las provincias de Salamanca y Cáceres).

v. 38 sovecientas: 'novecientas'.

v. 42 pan de perros y de perras: remite a la frase hecha «Dar pan de perro. Por dar pesadumbre, y dar mal trato" (Correas, Vocabulario, p. 896).

v. 46 que non debiera: bordoncillo muy repetido en la época. Ver Correas, Vocabulario, p. 1054: "Que no debiera. Que nunca debiera. Añádese a muchas razones arrepintiéndose, o retrayendo y quejándose. 'Fue, que no debiera'. 'Casose, que no debiera'. 'Vino, que no debiera'. 'Hablé una palabra, que no debiera... que nunca yo la hablara'; 'Fue allá, que nunca fuera... que no debiera'”.

v. 51 estantino: prevaricación por 'estantigua'. 
matadura, empeine, lepra, envidiando cuanto hago, ¿no queréis que me aburrezca y que hecho un tigre Ascanio dé conmigo en esas peñas? Todo cuanto hago me envidia: posturas, preitos, sentencias..., en que sean, cual podéis entender, de mi cabeza. Dice que es cosa devina, que envidia mucho mi cencia: si salgo a la calle dice que orearme es gran menestra, y si me estoy en mi casa,

que me envidia la pereza;

si me ve andar, si me paro, el vestido, la montera, si está la calza al revés o si la llevo derecha.

¿Queréis saber el agravio y la enjundia a lo que llegan? Pues mirad: yo tenía un hijo de esta sodomía mesma, bonito como una endrina, donoso como una breva, y tanto me lo envidió, dio en herle tan grandes fiestas, que el mochacho, de aborrido, se murió y se hue a la huesa. Vino, pues, este mal hombre a darme el pésame y entra diciendo: «En verdad, Alcalde, que os envidio la enterneza». ¡Válgate dos mil demoños,

v. 52 matadura: 'herida, llaga', pero llámase así también en sentido figurado al «hombre necio, molesto y pesado» (Autoridades). empeine: «es una especie de tińa seca que procede de cólera o flema sutil, podrecida o salada, que solamente ocupa el cuero o cutis exterior del cuerpo" (Autoridades).

v. 55 tigre Ascanio: prevaricación por ‘tigre Hircanio o Hircano’. Hircania es una región de Asia próxima al mar Caspio, por las inmediaciones de Armenia y Persia. La fiereza de sus tigres y panteras es proverbial: tratan de ello Plinio (Historia Natural, VIII, 66), Virgilio (Eneida, IV, 367), Pomponio Mela (Cosmografía, 3, 43), San Isidoro (Etimologías, 14, 501), Ravisio Textor (Officina, p. 419), Covarrubias (Tesoro) y un largo etcétera. Casi no hay ingenio del Siglo de Oro que no cite en una u otra ocasión al tigre hircano como ejemplo extremo de rabia o fiereza.

v. 56 conmigo] commigo P.

v. 59 en que sean: 'aunque sean'.

v. 64 menestra: posible prevaricación verbal por 'muestra', en el sentido de que salir a la calle a orearse ('airearse') es muestra de gran cencia ('ciencia', v. 62).

v. 72 enjundia: 'enjuria, injuria'.

v. 74 de esta sodomía: 'de esta manera, de este porte'. Pero nótese la barbaridad que dice el Alcalde.

v. 78 herle: 'hacerle'.

v. 80 se hue a la huesa: 'se fue a la fuesa o sepultura'.

v. 84 enterneza: 'entereza'. 
REgIDOR

Alcalde

Alcalde

REGIDOR

Alcalde

REGIDOR

Alcalde

REGIDOR

Alcalde sobre hueso, estauta, ruema, que de tu envidia seguro no tengo un dolor de muelas! ¡Ha dicho el señor Alcalde! ¡Mas que me envidia la lluenga!

\section{Sácasela}

Envidiar no es cosa mala, pues quien envidia desea lo bueno que ve en los otros. La villa, a su bien atenta, os ha hecho Alcalde, y yo, que soy Regidor, es fuerza, siendo fiscal en lo malo, aplaudir lo que se acierta.

Mirad, os dio Dios tal gracia, tal arte, tan gran prudencia, aquesa disposición, ese lleno, esa presencia... ¿El coram vobes?

¡El mismo!

Cuantas decís, son sentencias.

Pues digo que vus ahorquen,

y mi sentencia es aquesta.

Esa capa tan airosa,

ese talle, esas melenas,

esa barba...

\section{Tómasela}

Alcalde

¡Este garrote

que os reviente la cabeza!

¡Hay tan gran desvergonzado!

¡Mirad qué rara destreza

en jugar de aquesa vara!

Pues esperad, que de veras

juego también de mandoble.

¿Quién no envidia vuestras fuerzas?

Digo que decís verdad,

v. 84 estauta, ruema: posibles deformaciones lingüísticas por 'estatua' y 'reuma'.

v. 89 ¡Ha dicho el señor Alcalde!: ‘Así se habla, así de bien habla el señor Alcalde!'

v. 90 lluenga: 'lengua', aquí con el sentido de 'oratoria, discurso'.

v. 97 fiscal en lo malo: alude a la función principal de los regidores, que es ocuparse del "gobierno económico» (Autoridades).

v. 103 coram vobes: o coram vobis: «equivale a presencia buena y grave; y así del que es bien hecho y de buen talle, disposición y persona, o que afecta gravedad y compostura en ella, se dice que tiene gran coram vobis. Es voz familiar [...]. Vulgar y comúnmente se toma por la cara o rostro" (Autoridades). Véase, Tirso de Molina, La lealtad contra la envidia, vv. 1993-1995: "Compro un juro, I un mayorazgo opulento / que me ensanche el coram vobis»; Mateo Alemán, Guzmán de Alfarache, p. 688: "Gran añagaza es un buen coram vobis, gallardo gastador, galán vestido y don Juan de Guzmán».

v. 115 mandoble: alude a los palos que le va a dar con la vara si no deja de importunarle. 
que hueron nińas de teta

las huerzas de aquel gigante

Golilla, y de la ballena

de Juanas, pues que yo os sufro.

¡O so de bronce o so bestia!

Ya me han dado calosfríos,

veninos, granos, postemas...

Esto, si no es el Barbero,

¿quién ha de haber que lo entienda?

\section{Vase}

Alguacil Cierto, Regidor, que siento que así apuréis la paciencia de nuestro Alcalde. Mirad que esas burlas son muy necias.

REGIDOR Hombre, ¿no sabéis la enigma?: lo he metido en esta tema por que me tome ojeriza.

Alguacil ¿Y es buena amistad aquesa?

REgIDOR Sí, porque una vez metido en esta manía tan terca, no es menester para que haga cualquiera cosa bien hecha, sino el ver que a la contraria me aplico yo, y a la opuesta. Fuera de que el pasatiempo que lo haga corriente es fuerza, pues sin domarse los hombres no son hombres, sino fieras. Yo le he de hacer que sea hombre.

Alguacil Digo que es famosa empresa.

REGIDOR

Alguacil Ayudadme vos, y ahora que se va a la casa o tienda de el Barbero, tras él vamos. Pues vamos, si es cantaleta.

\section{Vanse. Salen el Barbero, Perucho y Garbosa}

BARBERO

Perucho, ven acá, dame otro abrazo. ¡El dotor de Alcalá! ¡El estudiantazo! Tu venida me llena de placeres.

vv. 119-120 aquel gigante / Golilla: el gigante Goliat.

vv. 120-121 la ballena / de Juanas: la ballena de Jonás.

v. 122 so: 'soy'.

v. 123 calosfrios: 'calofríos, escalofríos'.

v. 132 tema: 'manía, locura'.

v. 133 por que: 'para que', con valor final.

v. 150 cantaleta: 'burla, chasco, mofa'.

v. 152 Alcalá: la famosa Universidad de Alcalá de Henares. 
¡Válgate Peruchillo! ¿Que tú eres?

Perucho Sí, tío, que mi estudio ha sido grima.

¿No besaré las manos a mi prima?

BARbero Sí, sí, esta gran mujer. Llega, Garbosa,

habla a tu señor primo. [A Perucho] Es vergonzosa.

Garbosa Yo no hablo con primos ni conjuntos.

¡Oiga!, ¿en qué bodegón comimos juntos?

160

Perucho No se enoje mi prima, que no trato

de ponerle hipocóndrico el recato,

pues es el agridulce de las damas.

GARBosa Mas, jarre allá!, que hay primos con mil tramas

que quieren engañar a las mujeres.

Barbero ¡Válgate Peruchillo! ¿Que tú eres?

¡Oh, lo qué en Alcalá habrás estudiado!

¿Vienes de bachiller, o licenciado?

Habla, habla en tu estudio y ciencia experta,

que aquí te aguardo con la boca abierta.

Perucho Seis años hace hoy que en Alcalá triunfante

entré de polizón o de estudiante,

donde sin duda - con salud sea dicho-

asombró a las Escuelas mi capricho.

Cuanto a mi inclinación, maldita aquella

tuve a estudiar gramática, ni a olella,

por ser con sus latines y despachos

la gramática cosa de muchachos,

ciencia de hidalguetes hambroncillos,

que sin dar de comer, toda es palillos.

Aténgome a mi química, alegórica,

quiromántica, estante, pitagórica.

BARBERO

¡Aguarda! Poco a poco, no me encantes.

¿Qué es aquello de góricas y estantes?

Perucho

Todos son nombres proprios en Amberes.

BARBERO

¡Válgate Peruchillo! ¿Que tú eres?

Perucho

Fue mi arte de esferas y astrolabio,

con que de puro sabio

v. 155 grima: 'horrible, muy pesado e intenso'.

v. 159 primos, conjuntos: 'familiares, parientes'. Conjunto: «aliado y unido íntimamente con otro, y hecho uno con él mediante el vínculo estrecho de la sangre y parentesco, u de la amistad y confianza. En este significado es muy frecuente el uso de esta voz, y así en lo jurídico se dice del marido que es conjunta persona de la mujer; de los parientes y amigos, que son muy conjuntos» (Autoridades).

vv. 161-162 no trato / de ponerle hipocóndrico el recato: 'no es mi intención atentar contra su honestidad y recato'.

v. 172 polizón: «el sujeto ocioso y sin destino que anda de corrillo en corrillo» (Autoridades).

v. 176 gramática] grammatica $P$.

v. 178 gramática] grammatica $P$.

v. 179 hidalguetes hambroncillos: la figura del hidalgo hambrón cristaliza en la literatura con el escudero toledano descrito en el Lazarillo de Tormes, tratado III. Recuérdense asimismo estos versos de Quevedo, Poesía original completa, p. 764: «Un hidalgo de la guerra, / hambrón de todo picar».

v. 180 toda es palillos: porque tales hidalgos gustan de llevarse el palillo a la boca para aparentar que han comido recientemente. Recuerda la actitud del escudero en el Lazarillo de Tormes, p. 94: «Y por lo que toca a su negra que dicen honra, tomaba una paja, de las que aun asaz no había en casa, y salía a la puerta escarbando los que nada entre sí tenían».

v. 181 alegórica] allegorica P.

v. 185 Amberes: respuesta adecuada a la necedad del Barbero, con la cual Perucho se sale por la tangente, pues en realidad no dice nada especial o lógico, pero por eso mismo satisface la ignorancia del Barbero. 
BARbero

Perucho

BARBERO

Garbosa

Perucho

GARBOSA

Perucho

Garbosa

Perucho

Garbosa

BARBERO pude llamarme Alfonso.

¿Y te llamaste?

No, tío, que era dar con todo al traste.

190

Aprendí con orgullo

todas cuantas figuras tiene Llullo,

las de el docto Agramante, Tiridates,

Palamedes, Beroso y Amurates.

Señores, gran sobrino me ha venido,

y a Garbosilla y todo un gran marido.

¡Ah, muchacha, este primo es soberano!

¡Si entendiera de rayas de la mano!

¿Cómo es eso si entiendo, prima mía?

Descuídame esa mano en cortesía.

\section{Tómasela}

Mejor fuera de azotes.

¡Ay, mi mano!

No, prima, te alborotes,

que esto es formar las rayas bien formadas,

la vital y la hepáctica encontradas,

y este monte de Venus que al de Marte

205

mira por esta parte,

aquí con un cuadrado y acá un trino,

dice que un soldadillo golondrino,

porque tiene buen pico, te ha cuadrado.

No es cosa de cuidado.

Pero a no estar Saturno de por medio, que es el viejo, volaras sin remedio, ¿no es verdad?

¡A mí, sobrino, a mí!
Digo que habla con el diablo.

vv. 188-189 sabio... Alfonso: transparente juego con el nombre de Alfonso X el Sabio, rey de Castilla.

vv. 192-194 Llullo, Agramante, Tiridates, Palamedes, Beroso, Amurates: serie caótica de nombres raros y extravagantes, con resonancias clásicas, que el supuesto estudiante cita de carrerilla para impresionar a los demás. Llullo parece evocar a Marco Tulio Cicerón, citado siempre en el Siglo de Oro como Tulio; Agramante es el nombre de un personaje del Orlando furioso de Ariosto; Tiridates se llamaron varios reyes de Armenia; Palamedes es personaje de la mitología griega, rival de Odiseo; Beroso fue el autor de una historia de Babilonia (s. III a. C.); por último, Amurates se llamaba un famoso sultán del imperio otomano (s. XIV).

v. 201 azotes: en juego con la voz «mano» del verso anterior, remite a la frase hecha mano de azotes, que es una "cantidad determinada de azotes, como una docena, dos o tres» (Autoridades).

v. 204 vital, hepáctica: en el arte de la quiromancia son dos líneas de la mano perfectamente identificables. La línea vital es la más importante de todas, mientras que la hepática, que se considera secundaria, se refiere a la salud y se asocia con Mercurio.

v. 205 montes de Venus y Marte: así llaman los quirománticos a las pequeñas elevaciones de la mano que surgen en la base del dedo pulgar (Venus), y entre el dedo pulgar y el índice, así como bajo el dedo meńique (hay dos montes de Marte).

v. 207 cuadrado: en la quiromancia, los signos cuadrados que se localizan en la mano se consideran propicios y positivos.

v. 209 te ha cuadrado: 'te ha gustado, te ha enamorado', en juego de antanaclasis con el cuadrado del v. 207.

vv. 211-212 Saturno: en el arte de la quiromancia, el monte de Saturno se localiza en la raíz del dedo medio o corazón. Subyace asimismo un doble juego con el dios mitológico Saturno, representado como un anciano con luenga barba y cabellos blancos, al cual se alude con el adjetivo viejo del v. 212, que apunta maliciosamente hacia el padre de Garbosilla, o sea, el Barbero. 


\section{Toma la del viejo}

Perucho

BARbero

Perucho

Barbero

Perucho

BARBERO

Perucho

BARBERO

Perucho
Aqueste retablo

dice, tío, que usted tuvo viruelas

años ha, y hoy el número de muelas

uno es.

$\mathrm{Ni}$ aún medio, que han quedado en cero.

¿Pues puede estar sin muela si es barbero?

¡Oh, eso es verdad!

No fue más docta Ceres.

¡Válgate Peruchillo! ¿Que tú eres?

Olvidóseme un puncto muy curioso, admirable y famoso.

Vuélveme a dar la mano, prima mía.

Eso y dejarme a mí es alevosía.

Pues venga juntamente,

\section{$A$ los dos}

que es hacer a dos manos ser prudente.

\section{Sale el Alcalde}

\section{Alcalde}

BARBERO

Alcalde

Perucho

Alcalde

Perucho

BARBERO

Alcalde
¿No hay quien sepa sangrar en esta casa?

Cogionos con las manos en la masa

el Alcalde.

¡Por cierto!

Miren, y la emboscada y el enjerto.

¿Qué hacéis aquí?

$\mathrm{Y}$ es arte de tomaros mucha mano.

¿Tantas manos tomáis? Parecéis cura.

Es, señor, que les digo la ventura.

Es un poco gitano mi sobrino.
La vida en mi arte gano.

Veamos, mirá esta mano, y cepos quedos.

v. 214 retablo: parece remitir al aspecto viejo y arrugado de la mano del Barbero, quizás evocando algún refrán como este: «Hombre viejo, retablo de duelos» (Correas, Vocabulario, p. 396).

v. 218 muela: chiste dilógico que surge a partir del doble sentido de muela como 'parte de la dentadura, diente molar' y como 'piedra de afilar', la cual necesariamente ha de tener todo barbero para afilar sus herramientas de trabajo.

v. 219 Ceres: diosa romana de la agricultura y las cosechas, pero que aquí no viene a cuento mencionarla, en otra necedad más de Perucho.

v. 226 hacer a dos manos: el Maestro Correas en su Vocabulario, p. 961, recoge la siguiente frase: «Hace a dos manos. El que cumple con dos; y de dos partes tirar provecho".

v. 227 sangrar: 'sajar una vena para dejar salir la sangre excesiva o contaminada que -según se creía- generaba las enfermedades'. Hacer tales sangrías era oficio común de los barberos.

v. 228 con las manos en la masa: frase hecha que sigue vigente en la actualidad. Ver Correas, Vocabulario, p. 952: «Estar las manos en la masa. Tener las manos en la masa. Por estar dispuestos para hacer las cosas».

v. 232 tomaros mucha mano: además del sentido recto, subyace la alusión maliciosa al hecho de 'tomaros mucha confianza'.

v. 237 cepos quedos: «frase familiar con que se da a entender a alguna persona se sosiegue, aquiete y no haga mala obra a otro» (Autoridades). 
Perucho

Alcalde

Perucho

Alcalde

Perucho

Alcalde

Perucho

Alcalde

BARBERO

GARBOSA

Alcalde

BARBERO

Perucho

Alcalde

Perucho

Alcalde

Perucho

Alcalde
¿Con qué haremos la cruz?

Con esos dedos.

No sé yo hacer la cruz si no hay escote.

Pues yo os haré una cruz de un buen garrote.

Diga aquí.

Digo, pues, que un gran disgusto

trae el señor Alcalde.

¡Y grande susto!

Que teniendo el oficio mil golosos,

se merienda y se come de envidiosos.

¡Vive san... que es un sénico el mozuelo!

245

$Y$ tan de rabia vengo, tan en celo, que aquí me han de sangrar y han de darme

todo el beleño, sin que quede adarme.

Un Regidor me tiene desta suerte, un Regidor es causa de mi muerte,

sin ver que tengo esposa allá en Torrijos, seis gallinas, un puerco, con seis hijos.

¡Ay, señor!, ¿qué he de hacer con tantas penas?

Barbero, endegolladme aquestas venas.

No hay en casa lanceta.

El albéitar dará su ballestilla.

¡Qué mancilla!

No se apasione usted, señor Alcalde.

Téngase, que no en balde

tiene al mismo Mercurio en su presencia.

¿No sabremos de cierto la dolencia?

Hombre, ¿no lo acertaste ya en denantes?

Estas venas, de envidia están pujantes.

¡Qué! ¿El Regidor le envidia?

Ese me mata.

Pues yo sé medicina más barata.

¿Y cuál es?

v. 238 hacer la cruz: el quiromante o adivino (Perucho) hace la señal de la cruz sobre la mano del cliente (Alcalde) antes de echarle la buenaventura; pero es también una forma taimada de pedir dinero, como nos recuerda Cervantes en La gitanilla, pp. 90-91: «Denle, denle la palma de la mano a la nińa, y con qué haga la cruz - dijo la vieja-, y verán qué de cosas les dice, que sabe más que un doctor en medicina [...]. Todas la cruces, en cuanto cruces, son buenas; pero las de plata o de oro son mejores, y el señalar la cruz en la palma de la mano con moneda de cobre sepan vuesas mercedes que menoscaba la buenaventura».

v. 239 escote: 'pago'. Le está pidiendo una moneda para hacer su trabajo.

v. 243 oficio] officio P.

v. 245 sénico: 'cínico'.

v. 248 beleño: bebedizo con propiedades narcóticas que aquí se aplica a modo de anestesia.

v. 251 Torrijos: lectura tentativa, pues un roto en el folio 88v nos impide leer con claridad la palabra escrita originalmente.

v. 255 lanceta: especie de escalpelo, de punta muy fina, "con que el barbero abre la vena para sangrar» (Covarrubias, Tesoro).

v. 256 albéitar: 'veterinario'; ballestilla: «cierto instrumento de hierro, a modo de ballesta pequeńa, de que suelen usar los albéitares para sangrar las bestias caballares" (Autoridades).

v. 259 Mercurio: interpreto que Perucho quiere decir 'Galeno', pero en su ignorancia supina dice Mercurio, que suena raro, queda bien y nadie le entiende.

v. 261 denantes: 'antes'; vulgarismo. 
Perucho

Alcalde

Perucho

Alcalde

Perucho

Alcalde

Perucho

REgIDOR

Alcalde

REgIDOR

Perucho

Alcalde

Perucho

Alcalde

REgIDOR

Alcalde

REgIDOR

Alcalde

Regidor

Perucho

Alcalde

BARBERO

Alcalde

REGIDOR

Alcalde

REGIDOR
Dicen Báñez y Moscoso

265

que a un envidioso, echarle otro envidioso.

¿Ah, sí? Pues no tien cura mi modestia.

¿Por qué?

¿Yo he de envidiar aquella bestia?

Que es ademán no más.

¡Qué desatino!

Pues sepa que el remedio es peregrino.

270

\section{Salen el Regidor y el Alguacil}

Siguiendo os vengo, Alcalde, ...

¡Tome usté esto!

... que os envidio el veniros a este puesto.

Obre como le he dicho.

Diga, ¿yo he de envidiar aquella cara?

Vénzase y lo verá.

Vaya en fiado.

275

Mucho os envidio, Alcalde, lo atusado.

Oh, amigo Regidor, ¿quién vus compuso?

¡Cierto!, que el sombrerillo, que está al uso.

Esa cabeza igual y tan prudente.

No he visto Regidor más endecente.

280

Lo grave, lo sereno.

Vaya, Alcalde, adelante, que va bueno.

Hombre, ¡que ya no sé lo que me hablo!

Quien a este envidia, envidiará un diablo.

El remedio va obrando con poderes.

285

¡Válgate Peruchillo! ¿Que tú eres?

Por cierto, Regidor de aquesta villa,

que heis echado famosa pantorrilla.

Yo y todo, que os la envidio es cosa llana.

Es para con la vuestra, la mía enana.

290

¡Famoso está el capote!

Por cierto, que us envidio el buen bigote,

la nariz con su comba,

¡mirad ese gazguerro, esa balomba!

¡Qué! ¿Es chasco? Y si lo es, la calle gano.

v. 265 Báñez, Moscoso: nueva extravagancia de Perucho, que con la sola mención de estos dos apellidos -que carecen aquí de una significación especial- aparenta atesorar gran ciencia. Es posible que en el caso de Báñez se esté evocando al famoso teólogo dominico Domingo Bánez (1528-1604), pero no veo una conexión semejante con ningún Moscoso, salvo la rima directa con envidioso.

v. 266 otro envidioso] otro embioso P, errata.

v. 267 tien: 'tiene'; modestia: 'molestia, mal'.

v. 270 peregrino: 'eficaz, sorprendente’; "por extensión se toma algunas veces por extraño, raro, especial en su línea o pocas veces visto" (Autoridades).

v. 276 atusado: «el que está muy aseado, pulido y compuesto» (Autoridades).

v. 288 heis echado: 'habéis echado'.

v. 292 us envidio: 'os envidio'.

v. 294 gazguerro: 'garguero', esto es, la 'parte superior de la tráquea, cuello'; balomba: interpreto que quiere decir 'balumba', en el sentido de 'porte, todo el aderezo de la persona'. 


\section{AlCALDe}

Regidor

Alcalde

REgIDOR

Alcalde

Regidor

Alcalde

Regidor

Alcalde

Regidor

Alcalde

REGIDOR

Alcalde

Alguacil

Perucho

Alguacil

Perucho

Alguacil

Perucho

Alguacil

Perucho

Alguacil

Perucho

BARbero

GARBOSA

BARbERo

GarbosA

Barbero

GarbosA
¿Qué es iros? Aquí me heis de cumplir mano.

¡Voto a bríos que de envidia he de hartarle,

y que he hasta los zancajos de envidiarle!

Sí, pero aquese andar...

... $\tan$ estremados pies...

Aquesos pasos...

... el desenfado...

... $\tan$ lindos vasos...

300

... el derrengado, digo...

... mire aquella barriga...

... el arrojo de mano...

$$
\text { ... aquel ombligo... }
$$

... ese andar de tropel...

$$
\text { ... el manoteo... }
$$

$$
\text { ... ese floreo... }
$$

Vanse correspondiendo acciones, cada uno por su puerta, a compás

Alón.

Pechuga.

Tomate.

Zanahoria.

Buscón.

Podenco.

$$
\text { Cangrejo. }
$$

A lo dicho.

Araña.

$$
\text { ¡Cierra España! }
$$

Vanse los dos correspondiendo de la misma suerte

¡Hola!

Mar.

Garbosilla.

¿Ya estás en la destreza? ¿Digo algo?

A todo salgo.

309

Vanse también correspondiendo

FIN

v. 298 zancajos: los 'huesos de los talones' y, por metonimia, los 'pies'.

v. 305 Alón: «voz de la germanía. Es como interjección con que se excitan los que la usan para salir de alguna parte o apartarse de algún sitio, y vale tanto como 'vamos'. Es voz tomada del francés» (Autoridades). 


\section{SARAO AGITANADO ENTRE OCHO HOMBRES Y MUJERES}

\section{Salen las guias a la primera copla y van recibiendo a los otros}

Celebremos los tres de la fama que hoy honra la Iglesia con aclamación. Queme amor el desvelo en sus aras y rinda el tropel de las aves su voz.

Pocos son los penachos del viento, las plumas, los picos, son poco rumor si sus ecos el cielo no presta, pues vee que es tan suya la reputación.

Tres espíritus nobles Guzmanes en luz desafían los rayos del sol, pero el sol se les rinde, porque ellos del cielo el camino lo saben mejor.

La sagrada y honrosa tïara de un Pío eminente, supremo pastor, que con verse en el trono elevado también al desvelo sus sienes les dio.

De un Jacobo que, Adonis divino, las ninfas virtudes juraron de flor, cuando flor le corona la tierra, pasa en el cielo por exhalación. Margarita, la ciega de Umbría que tuvo de perlas la gracia y la voz, sin más ver y cerrados sus ojos, pudo a los doctos leerles lección.

De la gracia y virtudes no pudo dar testimonio ninguno mejor, que si no fue testigo de vista, aquí fue testigo de toda ecepción.

Acotación inicial guía: «la persona que en los saraos, bailes o danzas lleva tras sí a las demás de su coro o hilera» (Autoridades).

v. 1 los tres de la fama: se refiere a los tres dominicos que en 1672 fueron beatificados: el papa Pío V, Diego de Bebańa y Margarita de Castello. La noticia llegó a Manila con retraso y los fastos celebrativos tuvieron lugar en noviembre de 1676.

v. 9 Guzmanes: porque los tres nuevos beatos pertenecen a la Orden de Predicadores, fundada por Santo Domingo de Guzmán en 1216 .

vv. 13-14 tiara, Pío, supremo pastor: el primero de los festejados es Pío V (1504-1572), que alcanzó la tiara papal entre los años $1566-1572$.

v. 17 Jacobo: o sea, Diego de Bebaña, abogado de los quebrados. En la Loa segunda se le llama también con este mismo nombre: «Un Jacobo santo y docto, / pasmo de virtud y ciencia [...]. / Mira y alaba un Jacobo, / dechado de penitencia, / de retiro, de oración, / como esmero de las letras» (Sagrada fiesta 90v y 91r).

v. 21 Margarita, la ciega de Umbría: Margarita de Castello (1287-1320), que fue ciega y coja, es considerada patrona de los discapacitados. La Loa segunda recuerda algunos de sus méritos: «Una Margarita, quien / por la gracia más perfecta / dio los ojos de la cara / y fue de balde la venta [...]. / De una Margarita mira / la más abundante vena / de virtud que en sus montańas / la Umbría fértil respeta» (Sagrada fiesta 90v y 91r). 


\section{PAVANA}

Venga Apolo a dar con su lira más divina alabanzas al Guzmán, pues se ve de pompa rica aclamar su ancianidad por tres hijos que la Iglesia le coloca en el altar: tres hachas tiene más.

Musas, venid, cantad, vuestros ecos se repitan por el aire, tierra y mar, que en el golfo ya registra tres fanales la piedad, tres colosos que Domingo añadiendo al mundo está: tres hachas tiene más.

Manila da lugar, tan famosa con sus islas, de la luz puerta oriental, cuando nuestros santos miras y el ejemplo que te dan. Da tus plácemes al cielo, que si así los supo honrar, tres hachas tiene más.

¡Oh tú, hermosa deidad!, religión siempre aplaudida, forma cada día más.

Dale al cielo piedras vivas

y a sus muros de cristal, que hoy, por ver en tus diamantes fondo, luz y calidad, tres hachas tiene más.

\section{GALLARDA}

Diferencia y majestad

la gallarda pide hoy, porque va de auctoridad de la Iglesia la atención.

Que nos mira una ciudad cortesana con primor, una Audiencia y Tribunal

Pavana: «especie de danza española que se ejecuta con mucha gravedad, seriedad y mesura, y en que los movimientos son muy pausados, por lo que se le dio este nombre con alusión a los movimientos y ostentación del pavo real» (Autoridades).

Gallarda: danza muy difundida en la Europa del Renacimiento, con movimientos vivos y enérgicos. Calderón de la Barca la describe con cierto detalle: «La reverencia ha de ser, / grave el rostro, airoso el cuerpo, / sin que desde el medio arriba / reconozca el movimiento / de la rodilla; los brazos / descuidados, como ellos / naturalmente cayeren; / y siempre el oído atento / al compás, señalar todas / las cadencias sin afecto. / ¡Bien! En habiendo acabado / la reverencia, el izquierdo / pie delante, pasear / la sala, midiendo el cerco / en su proporción, de cindo / en cinco los pasos. ¡Bueno!» (El maestro de danzar 1561). 
de Real elevación,

el Cabildo y Regimiento

de la plaza siempre invicta,

de la perla del oriente

que es la corte de Manila.

Su apostólico Cabildo

de la catedral nos mira,

a quien sigue en el teatro

75

noble y docta clerecía.

Las sagradas religiones

que han venido a nuestra fiesta,

todas llenas de blasones

de virtud, ejemplo y letras.

El real campo de nobles

valerosos en la guerra,

cada cual a Marte pone

una escuela de destrezas.

El concierto, unión y arte

aplaudiendo están las damas,

hechas Argos por cantarle

al de más aire la gala,

para que ingeniosa acabe

con sus golpes la gallarda,

y sus cinco pasos hallen

por millares alabanzas.

\section{DESPEDIDA}

Celebremos los tres de la fama, todos juntos el víctor les demos, que la música, voces y lazos

nunca vieron mejores encuentros.

Al compás que los cielos nos mueven, agradables, piadosos, parejos, vaya amor ajustando sus pasos, vaya dando obediente respectos.

Con su cuenta y desvelo las guías, den al séquito leyes y ejemplo, que es la fiesta de números toda y celebra aclamado el concierto.

Por sus claros, sus hilos, sus lados, entren todos tomando sus puestos, que por regla de tres se reducen cuantas galas al día le vemos.

v. 71 perla del oriente: famoso apelativo con que se conocía la ciudad de Manila en los siglos de presencia española.

v. 73 apostólico] Appostólico P.

Su apostólico Cabildo: se refiere al cabildo catedralicio, diferente del cabildo civil o corporación municipal citado en el v. 69.

v. 87 hechas Argos: 'mirando atentas, vigilantes, sin perder un detalle', pues Argos fue un gigante mitológico caracterizado por tener cien ojos y no dormirse por completo nunca.

v. 91 cinco pasos: ver Calderón de la Barca: «Y así son los cinco pasos / los que doy y los que pierdo, / por la gallarda empezando» (El maestro de danzar 1561). Pormenores sobre estos cinco pasos y la música que les acompaña en Espejo Aubero, 107-108. 
Al pisar con airoso cuidado, den los pies prevenidos y prestos un aviso no más a la tierra, uno y muchos avisos al cielo. Ya parece que va a rematarse, por no dar en cansado, el festejo, mas por no retirarse de tropa, hagan dos el retiro primero. Por el mismo concierto les siguen, no sin quejas, los dos compañeros, que su breve cortejo se acaba y se queda en su ser el empeño.

Para hacer el forzoso vïaje los siguientes se van disponiendo, por que llegue a gozarse acabado lo que aspira a mirarse perfecto. Tengan fin, adalidades bizarros, la destreza, el cuidado y el juego, y la que es reverencia a los santos sea cortés al teatro respeto. 


\section{Bibliografía}

Alemán, Mateo. Guzmán de Alfarache. Francisco Rico (ed.). Barcelona: Planeta, 1983.

Anónimo. Lazarillo de Tormes. Francisco Rico (ed.). Madrid: Cátedra, 1987.

Autoridades. Diccionario de Autoridades (1726-1739). Madrid: Gredos, 1990. 3 vols. Edición facsímil.

Cabrero Fernández, Leoncio. "Orígenes y desarrollo del teatro en Filipinas». Anales de Literatura Hispanoamericana, 2-3 (1973-1974): 83-96.

Calderón de la Barca, Pedro. El maestro de danzar. Ángel Valbuena Briones (ed.). Obras completas. I, Comedias. Madrid: Aguilar, 1991.

Cateh. Catálogo del Antiguo Teatro Escolar Hispánico. Base de datos a cargo de Julio Alonso Asenjo. [Accesible en: http://parnaseo.uv.es/Ars/teatresco/BaseDatos/ Bases_teatro_Escolar.htm].

Cervantes, Miguel de. La gitanilla. Novelas ejemplares. Juan Bautista Avalle-Arce (ed.). Madrid: Castalia, 1985, vol. I.

Correas, Gonzalo de. Vocabulario de refranes y frases proverbiales (1627). Madrid: Castalia, 2000.

Covarrubias, Sebastián de. Tesoro de la lengua castellana o española (1611). Madrid: Iberoamericana, 2006.

Donoso, Isaac. «La literatura filipina en español durante la era barroca». Humanities Diliman, 13.1 (2016): 23-61.

Espejo Aubero, Amparo y Alicia. Glosario de términos de la danza española. Madrid: Esteban Sanz, 2001.

Fernandez, Doreen G. «Pompas y Solemnidades: Church Celebrations in Spanish Manila and the Native Theater». Philippine Studies, 36.4 (1988): 403-426.

Fernandez, Doreen G. Palabas: Essays on Philippine Theatre History. Quezon City: Ateneo de Manila University Press, 1996.

Hernández, Alonso. Historia eclesiástica de nuestros tiempos. Toledo: Viuda de Pedro Rodríguez, 1611.

Hernández Reyes, Dalia. «Comedias a lo divino: el teatro en las celebraciones religiosas novohispanas en tiempos de Carlos II». Judith Farré Vidal (ed.). Teatro y poder en la época de Carlos II. Fiestas en torno a reyes y virreyes. Madrid: Iberoamericana, 2007: 146-171.

Hill, Mattew J. K. Intercolonial Currents: Printing Press and Book Circulation in the Spanish Philippines, 15711821. Austin: The University of Texas at Austin-Texas Scholar Works, 2015. [Accesible en: http://utexas-ir. tdl.org/handle/2152/31619].

IRVING, David. "Musical politics of empire: the loa in $18^{\text {th }}$ century Manila». Early Music, 32.3 (2004): 384-402.
Irving, David. «Historical and literary vestiges of the villancico in the Early modern Philippines». Tess Knighton y Álvaro Torrente (eds.). Devotional Music in the Iberian World, 1450-1800: The Villancico and Related Genres. Aldershot: Ashgate Publishing Company, 2007: 363-398.

LARA, Eva. «Hechiceras celestinescas y nigromantes en la literatura del siglo xvı: ¿De la hechicera venida a más al mago venido a menos?» Eva Lara y Alberto Montaner (coords.). Señales, portentos y demonios. La magia en la literatura y la cultura españolas del Renacimiento. Salamanca: Sociedad de Estudios Medievales y Renacentistas, 2014: 367-432.

Morga, Antonio de. Sucesos de las Islas Filipinas. México: Gerónimo Balli, 1609.

Ocio y Viana, Hilario María. Reseña biográfica de los religiosos de la provincia del Santísimo Rosario de Filipinas desde su fundación hasta nuestros días. Manila: Real Colegio de Santo Tomás, 1891. 2 vols. [Accesible en la Biblioteca Digital Hispánica: http://bdh-rd.bne.es/ viewer.vm?id=0000015763\&page $=1$ ].

Ocio y Viana, Hilario María. Compendio de la Reseña biográfica de los religiosos de la Provincia del Santísimo Rosario de Filipinas desde su fundación hasta nuestros días. Manila: Real Colegio de Santo Tomás, 1895. [Accesible en: https://archive.org/details/ ark1148.0001.001.umich.edu].

Pardo, Felipe. Sagrada fiesta, tres veces grande, que en el discurso de tres días celebró el convento de Sancto Domingo de Manila, primera Casa de la Provincia del Sancto Rosario de Filipinas. En la beatificación de los gloriosos Sanctos Pio Quinto, Diego de Bebaña y Margarita de Castello. Mandada por nuestro Reverendo Padre Maestro Fray Juan Tomás de Rocaberti, Maestro General de toda la sagrada Orden de Predicadores. Y ejecutada por el Reverendo Padre Fray Felipe Pardo, Comisario del Sancto Oficio y Provincial segunda vez de dicha Provincia... Con las licencias del Gobierno y del Ordinario. Manila: Collegio y Universidad de Sancto Tomás de Aquino. Por el Capitán D. Gaspar de los Reyes. Año de 1677.

Quevedo, Francisco de. Poesía original completa. José Manuel Blecua (ed.). Barcelona: Planeta, 1981.

Retana, Wenceslao Emilio. Aparato Bibliográfico de la Historia General de Filipinas. Madrid: Sucesora de M. Minuesa de los Ríos, 1906. Hay edición facsímil en Manila: Pedro B. Ayuda y Compañía, 1964. [Accesible en la Biblioteca Digital Hispánica: http:// bdh-rd.bne.es/viewer.vm?id=0000188475\&page $=1]$.

Retana, Wenceslao Emilio. Noticias histórico-bibliográficas de el teatro en Filipinas desde sus origenes hasta 1898. Madrid: Victoriano Suárez, 1910. [Accesible en 
la Biblioteca Digital Hispánica: http://bdh-rd.bne.es/ viewer.vm?id=0000073158\&page $=1]$.

Rodrigo, Martín. «Tabacalera, tendiendo puentes durante más de cien años». Perro Berde, 4 (2013). [Enlace electrónico: http://www.perroberde.com/ pb04/tabacalera-tendiendo-puentes/] [Consulta: 5 de junio de 2016].

Sánchez del Castellar, Joseph. Descripción festiva y verdadera relación de las célebres pompas y esmerados aciertos con que la sagrada religión de la Compañia de Jesús aplaudió gozosa en estas Filipinas la canonización de su gran Padre San Francisco de Borja, y beatificación del beato señor rey don Fernando, y del beato Estanislao Koska. Manila: Imprenta de la Compañía de Jesús, 1674. [Accesible en la Biblioteca Digital Hispánica: http://bdh-rd.bne.es/viewer.vm?pid=d-2164379].

Santos, Ruperto C. (ed. y trad.). Anales Ecclesiásticos de Philipinas, 1574-1682. Manila: The Roman Catholic Archbishop of Manila, 1994. 2 vols.

Simonatti, Selena. «La Peña Camasia (y sus diablos): ¿un lugar recuperado?» Revista de Filología Española, XCV, 2 (2015): 339-358.
Summers, William J. «The Jesuits in Manila, 1581-1621: The Role of Music in Rite, Ritual, and Spectacle». John W. O'Malley et alii (eds.). The Jesuits, I: Culture, Sciences, and the Arts, 1540-1773. Toronto: University of Toronto Press, 1999: 659-679.

Tirso de Molina. La lealtad contra la envidia. Miguel Zugasti (ed.). Kassel, Reichenberger, 1993.

VIndel, Pedro. Biblioteca Oriental. Comprende 2747 obras relativas a Filipinas, Japón, China y otras partes de Asia y Oceanía. Madrid: P. Vindel, 1911-1912, 2 vols. [Accesible en la Biblioteca Digital Hispánica: http:// bdh-rd.bne.es/viewer.vm?id=0000015605\&page=1].

Zugasti, Miguel. «Santa Rosa de Lima, una santa del pueblo con sus fiestas y comedias para el pueblo». José M. Díez Borque, M. Soledad Arredondo Sirodey, Ana Martínez Pereira y Gerardo Fernández San Emeterio (eds.). Teatro español de los Siglos de Oro: dramaturgos, textos, escenarios, fiestas. Madrid: Visor, 2013: 117-151.

Zugasti, Miguel. «América en el teatro español del Siglo de Oro: repertorio de textos». Cuadernos de Teatro Clásico, 30 (2014): 371-410. 
